\title{
Mobilizing Inuit Qaujimajatuqangit in Narwhal Management through Community Empowerment: A Case Study in Naujaat, Nunavut
}

\author{
Erin Keenan, ${ }^{1}$ Lucia M. Fanning ${ }^{1,2}$ and Chris Milley ${ }^{1}$
}

(Received 21 February 2017; accepted in revised form 16 October 2017)

\begin{abstract}
This research examines the relationship between government wildlife management and the use of Inuit knowledge or Inuit Qaujimajatuqangit (IQ) through a case study focusing on narwhal (Monodon monoceros) harvesting in the community of Naujaat, Nunavut. Since Fisheries and Oceans Canada (DFO) introduced a community quota system in 1971, the ultimate responsibility for decision making has shifted from hunting communities to government. This shift corresponds with changes in the use of IQ within the community. Interviews with hunters, elders, and representatives of the hunters and trappers organization in Naujaat provide insight into the nature of these changes. Key factors influencing the role of IQ in narwhal management decision making included the imposed quota system, the perception of the ongoing role of IQ, communication challenges, modern-day drivers of change, and the lack of decision-making authority at the community level.
\end{abstract}

Key words: Inuit Qaujimajatuqangit; community empowerment; marine mammal management; Nunavut

RÉSUMÉ. Cette recherche examine le lien entre la gestion de la faune faite par le gouvernement et l'utilisation des connaissances des Inuits, aussi appelées Inuit Qaujimajatuqangit (IQ) grâce à une étude de cas portant sur la chasse au narval (Monodon monoceros) réalisée dans le hameau de Naujaat, au Nunavut. Depuis que le ministère des Pêches et Océans du Canada (MPO) a mis en place un système de quota communautaire en 1971, la responsabilité ultime en matière de prise de décisions est passée des mains des collectivités faisant la chasse aux mains du gouvernement. Ce virage a donné lieu à des changements en matière d'utilisation de l'IQ dans la région. Des entrevues avec des chasseurs, des aînés et des représentants de groupements de chasseurs et de trappeurs de Naujaat ont permis de comprendre la nature de ces changements. Parmi les facteurs-clés exerçant une influence sur le rôle de l'IQ en matière de décisions prises pour la gestion des narvals, notons le système de quotas qui a été imposé, la perception du rôle continu de l'IQ, les problèmes de communication, les moteurs du changement contemporains et l'absence de pouvoir décisionnel au niveau communautaire.

Mots clés : Inuit Qaujimajatuqangit; autonomisation des communautés; gestion des mammifères marins; Nunavut

Traduit pour la revue Arctic par Nicole Giguère.

\section{INTRODUCTION}

The Nunavut Land Claims Agreement (NLCA), signed in 1993 between the Government of Canada and Tunngavik Federation of Nunavut (the precursor to Nunavut Tunngavik Incorporated), created the territory of Nunavut and acknowledged the rights of Inuit to participate in the management of land, water, and wildlife resources (GC, 1993). Since then, efforts have been underway to establish resource management regimes in Nunavut that meet Inuit needs and account for Inuit values, culture, and knowledge (Boudreau and Fanning, 2016). The term Inuit Qaujimajatuqangit (IQ) emerged in the context of the creation of the Territory of Nunavut as a means of articulating the unique Inuit perspectives that would be the basis for decision making in the new territory (Wenzel, 2004). IQ encompasses Inuit knowledge, ways of knowing, values, culture, language, social organization, and decisionmaking practices. Rapid changes in the social, economic, and environmental realities of life in Nunavut have dramatically altered the context in which IQ is produced, expressed, and transmitted, complicating the relevance of IQ to addressing the issues currently facing Inuit (Tester and Irniq, 2008).

Nunavut's predominantly Inuit population of 35944 is distributed across 25 communities in three regions (Statistics Canada, 2016). Inuit lifestyles have changed dramatically since the $1950 \mathrm{~s}$, when the Government of Canada resettled the nomadic Inuit into permanent communities, transforming their traditional methods of hunting and traveling via sea ice (Wenzel, 1995). Traditional practices still shape Inuit livelihoods given the continued importance of subsistence hunting and other activities, and IQ informs these activities and Inuit social norms and cultural values.

The perceived value of Indigenous knowledge systems has been well documented; the United Nations Declaration on the Rights of Indigenous Peoples acknowledges

\footnotetext{
${ }^{1}$ Marine Affairs Program, Dalhousie University, 1355 Oxford Street, Halifax, Nova Scotia B3H 1R2, Canada

${ }^{2}$ Corresponding author: lucia.fanning@dal.ca

(C) The Arctic Institute of North America
} 
that "respect for Indigenous knowledge, cultures, and traditional practices contributes to sustainable and equitable development and proper management of the environment" (UN, 2008:2). The benefits of integrating Indigenous knowledge into resource management include enhancing our understanding of the resource to improve problem identification and framing of objectives, as well as building trust between knowledge holders by identifying commonalities and establishing shared interests (Dale and Armitage, 2011). Together, these benefits mitigate conflict associated with resource management decisions and result in more effective and inclusive management (Denny and Fanning, 2016). Thus, resource management problems in Nunavut represent opportunities to create spaces for Inuit empowerment within management, allow for IQ to act as the basis for decision making, and ensure that management meets Inuit needs (ITK, 2017).

Analysis of the relationship between government management of narwhal (Monodon monoceros) and the use of IQ at the community scale provides insight into how approaches to resource management in Nunavut can better address Inuit needs and perspectives. Inuit have hunted narwhal for subsistence for centuries. The Government of Canada began regulating the fishery in 1971 by enacting the Narwhal Protection Regulations, which introduced a quota system that limited the catch of each hunter (DFO, 2013). While the overarching policies have been amended in the intervening decades, the current approach is still based on an annual quota for each harvested narwhal population. Globally, the narwhal is not harvested commercially anywhere at present, and the species was not targeted by commercial whaling activities of the 19th and early 20th centuries to the same extent as other Arctic whales (McLeish, 2013). International antiwhaling interests have played a minimal role in shaping Canadian narwhal management. However, climate change, recent ice entrapments of narwhal, and the legacy of the anti-sealing movement contribute to mistrust between Inuit, environmentalists, and government managers. This mistrust has its roots in the perception that these latter two groups are acting in the interest of conservation at the expense of Inuit livelihoods (Rodon, 1998; Phelps Bondaroff and Burke, 2014).

This study uses responses from personal interviews and community input through local radio in the Hamlet of Naujaat (formerly Repulse Bay, Fig. 1) to explore how narwhal management in Nunavut might better reflect Inuit objectives and priorities and how Inuit control of the management process may be established to promote the decolonization of Nunavut wildlife management and meaningful inclusion of IQ.

\section{Narwhal Management System}

Before 1971, Inuit autonomously controlled narwhal harvesting activities (DFO, 2013). Sharing practices and cooperative hunting have been central components of

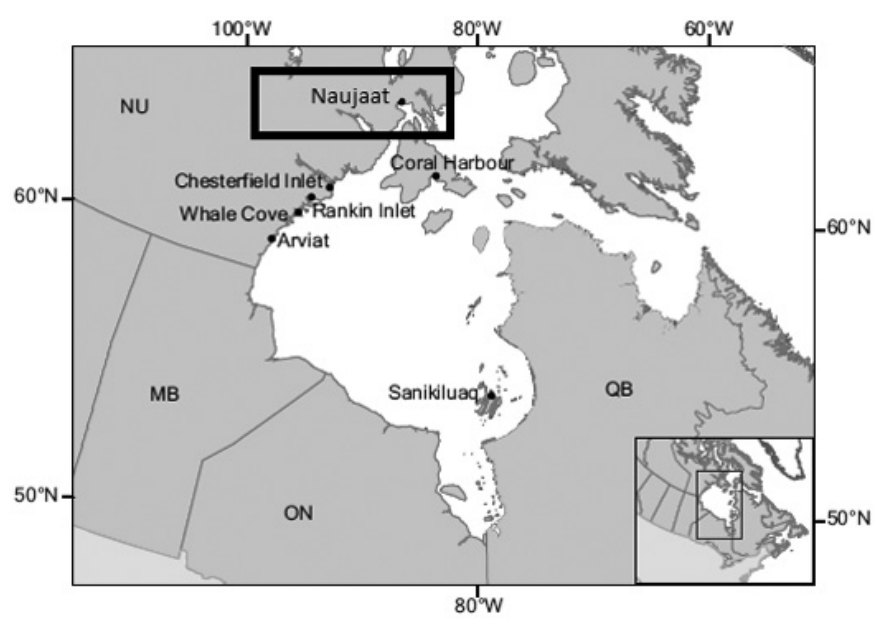

FIG. 1. Map showing Naujaat (formerly Repulse Bay), where the interviews took place, and other Hudson Bay communities.

all Inuit harvesting activities from the nomadic era to the present, and they continue to guide decision making about hunting at the scale of families and communities (Sejersen, 2001). Hunting tools have adapted over time from kayaks and harpoons to include rifles and motorized boats as a result of interactions and technology-sharing between Inuit and non-Inuit, especially 19th and 20th century European commercial whalers (Freeman et al., 1998; Hurtubise, 2016).

In 1977, the annual catch quotas for individual hunters introduced by the Narwhal Protection Regulations in 1971 were replaced by quotas for each community. When the Marine Mammal Regulations replaced the Narwhal Protection Regulations in 1993, the community quota system remained in place (DFO, 2013). The current regulations restrict narwhal harvesting to Inuit, but make no reference to the use of traditional, local, or Indigenous knowledge.

Currently, the decision-making process for narwhal management in Nunavut involves the convergence of DFO recommendations and scientific information with the views of Inuit (Fig. 2). Inuit knowledge and perspectives are represented at the community level through Hunters and Trappers Organizations (HTOs). The HTOs represent their communities through their respective Regional Wildlife Organizations (RWO), which advocate on behalf of the region by communicating with the Nunavut Wildlife Management Board (NWMB). The DFO, under the provisions of the Fisheries Act and the NLCA, engages with the NWMB and develops management proposals informed by scientific research, community consultations, and the national public interest. The Government of Nunavut (GN) and Inuit associations (Nunavut Tunngavik Incorporated and three regional Inuit associations) can opt to participate but do not have an NLCA-defined role. In accordance with the Fisheries Act and the Species at Risk Act, the DFO draws on the available science and consultations with other stakeholders to develop an Integrated Fisheries Management Plan or other management measures. The NWMB conducts 


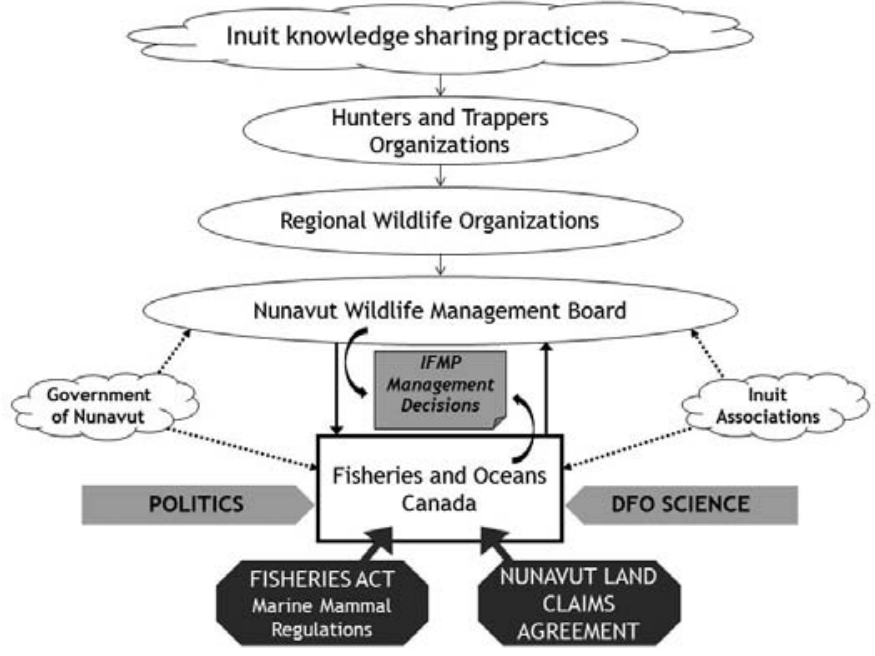

FIG. 2. Decision-making process for management of the Northern Hudson Bay narwhal population in Nunavut. "IFMP" = the Integrated Fisheries Management Plan.

its own consultations with co-management partners and stakeholders on proposed management recommendations, including public hearings, and makes recommendations on proposals to the Minister of Fisheries and Oceans. The Minister then decides whether to accept the NWMB recommendations and enact the management measures. The current Integrated Fisheries Management Plan was approved by the NWMB in 2012 (NWMB, 2012).

\section{Setting the Conceptual Context}

The principal conceptual frameworks underlying this research are Inuit Qaujimajatuqangit, co-management, and decolonization. The term Inuit Qaujimajatuqangit was first used in the context of management and governance during the drafting of the NLCA and subsequent creation of the Territory of Nunavut, as a term encompassing the breadth and depth of Inuit perspectives to be reflected in Nunavut governance. Many authors emphasize the "seamless" and non-reductionist qualities of IQ as a non-disciplinary knowledge system, as compared to reductionist, disciplinebased Western knowledge systems (Nadasdy, 2003; Wenzel, 2004; Huntington, 2005; Tester and Irniq, 2008; Boudreau and Fanning, 2016). The Nunavut Wildlife Act (2003) provides a more detailed guide for the use of IQ in management and decision making by describing 13 specific IQ concepts and their associated implications for wildlife management, and this Act has shaped subsequent policies for other aspects of the territorial government (GN, 2003).

Co-management is an approach to decision making in which power is shared between two or more entities, one of which is usually the government. The degree of power sharing varies across co-management arrangements, but the general purpose is to ensure that management reflects the needs, values, and knowledge of stakeholder groups (Rodon, 1998). In Nunavut, the NLCA mandates that wildlife issues are addressed through co-management intended to bridge Inuit and non-Inuit needs and interests. In the case of narwhal, the Government of Canada retains collaboration with the NWMB, Inuit organizations (Nunavut Tunngavik Incorporated, HTOs, and RWOs), and others (Fig. 3) (Boudreau and Fanning, 2016). The NWMB is the primary instrument for wildlife management and coordinates the co-management process (GC, 1993). The existing co-management framework in Nunavut could represent a mechanism for the mobilization of IQ for decision making, but this approach would require a powersharing structure that empowers Inuit.

Co-management arrangements across Canada, including those in Nunavut, have demonstrated a consistent failure on the part of government to share power in a way that allows for the meaningful inclusion of Indigenous knowledge systems in decision making (Stevenson, 2004; Giles et al., 2016; ITK, 2017). However, improving efforts aimed at co-management between the Canadian government and Inuit may be further complicated by international agreements that mandate science-based decision making, including the Convention on International Trade in Endangered Species of Wild Fauna and Flora (CITES) (CITES, 1973). Rodon (1998:131) describes the co-management process in Nunavut as "co-optation" into accepting the standards of a science-based approach for wildlife management, such as the use of quotas and hunting seasons, which undermines, rather than mobilizes, Indigenous knowledge systems.

Many of the issues with power disparities in Canadian co-management arrangements are rooted in Canada's colonial history and its legacy. The impact of colonialism, along with a century of rapid technological change, threatens the existence of Indigenous knowledge systems (Russell, 1997; Battiste, 2009). However, the use of Indigenous knowledge systems has gained political traction as a tool of resistance to colonial hegemony to advance decolonization (Simpson, 2004; Corntassel, 2012). Decolonization requires that both settler and Indigenous societies recognize how colonialism continues to manifest itself in present-day governance and social values. In Nunavut, decolonization requires removing or managing barriers to Inuit self-determination to ensure that Inuit can control both how resources are defined, accessed, used, and managed and the terms of reference for making decisions and setting objectives in the management process, which includes reconciling international obligations with a management system that empowers Inuit. The NLCA advanced Inuit autonomy over Nunavut, but the federal government and non-Inuit interests retain significant institutional power and social influence.

\section{THE CASE STUDY}

To examine the extent to which IQ influences wildlife management decisions in Nunavut, we chose a case study approach that narrowed the scope of the research while still 
allowing a detailed analysis of the research question (Tellis, 1997; Yin, 2013). The limitation of this approach is that it can be challenging to draw conclusions at the territorial scale from one case study; further research may be required to assess the applicability of the results to a broader scale.

\section{Significance of Hunting}

Marine mammal harvesting continues to be an important contributor to food security in the Arctic. The harvest provides food that is healthy and culturally appropriate in communities where store-bought food is often prohibitively expensive and may not represent Inuit dietary preferences (GN, 2008). Maktaaq, the skin of beluga (Delphinapterus leucas, Linnaeus, 1758), bowhead (Balaena mysticetus, Linnaeus, 1758), and narwhal, is a nutritious, highly valued food, and consumption of maktaaq provides a link between present-day hunting, historical activities of Inuit, and the cultural values connecting them (Freeman et al., 1998). Inuit communities also derive monetary benefits from narwhal harvesting (Hoover et al., 2013). Narwhal products are permitted for sale within Canada and, at present, internationally, under the conditions of CITES. Narwhal tusks can be carved into artwork and jewelry and sold to generate income. Unaltered tusks are sold for up to Can $\$ 100$ per foot or Can $\$ 15$ per inch. Hoover et al. (2013) assessed the overall economic value of beluga and narwhal harvesting in Naujaat to be equivalent to 3.3\% of the income of the average wage earner in Naujaat, with the value to the community (including food value) estimated at Can $\$ 1890$ per narwhal.

\section{Narwhal Population Status and Threats}

Narwhals are found almost exclusively in the waters of Nunavut and western Greenland (Richard, 2001). The global population is estimated to be more than 150000 (DFO, 2015). The Northern Hudson Bay population is one of two populations in Nunavut and the only one harvested by hunters from Naujaat and other Kivalliq communities (Asselin et al., 2012). The most recent 2011 DFO survey of the Northern Hudson Bay population estimated the population size as 12485 individuals on the basis of data collected through aerial surveys of summering areas (Asselin et al., 2012). Aerial surveys can be limited by poor weather and sea ice conditions and by uncertainty about narwhal distribution and behaviours (Laidre et al., 2015). The study area for the 2011 survey was designed in part to incorporate areas identified in traditional knowledge reports and was expanded in response to recommendations made by Arviq HTO members during a meeting with the DFO prior to the survey (Asselin et al., 2012).

In 2004, the Committee on the Status of Endangered Wildlife in Canada (COSEWIC) designated narwhal as a species of "special concern" because of estimates indicating that the population could decline by $30 \%$ over 30 years if hunting pressures were not reduced, data from the
2000 survey, and general uncertainty regarding population trends (COSEWIC, 2004). Internationally, the narwhal is a CITES Appendix II-listed species, and management authorities, including the DFO, are required to demonstrate that harvesting is sustainably managed and that the export of narwhal products does not pose a threat to the population (DFO, 2013). Accountability to CITES signatories in the international community can influence the decision-making process within Canada. Given the gaps in our knowledge about narwhal population dynamics, it is challenging to characterize and quantify specific threats to the species. Climate change, Arctic shipping, and seismic surveys are potential habitat disruptors (Shadbolt et al., 2015), and increased predation by orcas (Orcinus orca, Linnaeus, 1758 ) and mortalities from ice entrapments could threaten population numbers (Gonzalez, 2001; Laidre et al., 2008; Higdon and Ferguson, 2009; Ferguson et al., 2012; HeideJørgensen, 2013).

\section{Research Site - Naujaat, Nunavut}

The hamlet of Naujaat is a predominantly Inuit community in the Kivalliq region of Nunavut, on Repulse Bay at the northern entrance of Roes Welcome Sound (Fig. 1). The area forms part of the primary summering area of the Northern Hudson Bay narwhal population. The community's population of 1082 is mostly Inuit (> 90\%) with more than $60 \%$ of residents aged under 25 (Statistics Canada, 2016). Naujaat identifies itself as a community that emphasizes Inuit traditions, including a hunting culture, and the young population suggests that hunting pressures may be increasing as more hunters learn about narwhal harvesting practices (Hamlet of Naujaat, 2015).

The DFO has no representatives in Naujaat; the local Government of Nunavut conservation officer is responsible for enforcing wildlife management regulations, while the Arviq HTO manages local-level hunting and wildlife issues. From 1999 to 2002, Naujaat was one of six Nunavut communities participating in a joint federal DFO/NWMB trial community-based narwhal management program that the NWMB introduced in response to community concerns about existing management approaches. Under the supervision of the NWMB and DFO, HTOs in participating communities became responsible for establishing and enforcing bylaws and reporting back to the NWMB. Community quotas were removed, but total allowable catch limits remained in place and communities were required to meet specific regulations on harvesting methods, monitoring, and reporting. Insufficient communication between the NWMB, the DFO, and the communities regarding how quotas would apply led to the failure of the program; participating communities' perception of their authority was undermined when higher than expected catch and struck-and-lost rates for narwhal provoked the DFO to unilaterally close the entire fishery for the 1999-2000 season (Armitage, 2005). The NWMB discontinued the community-based management program in 2011. 


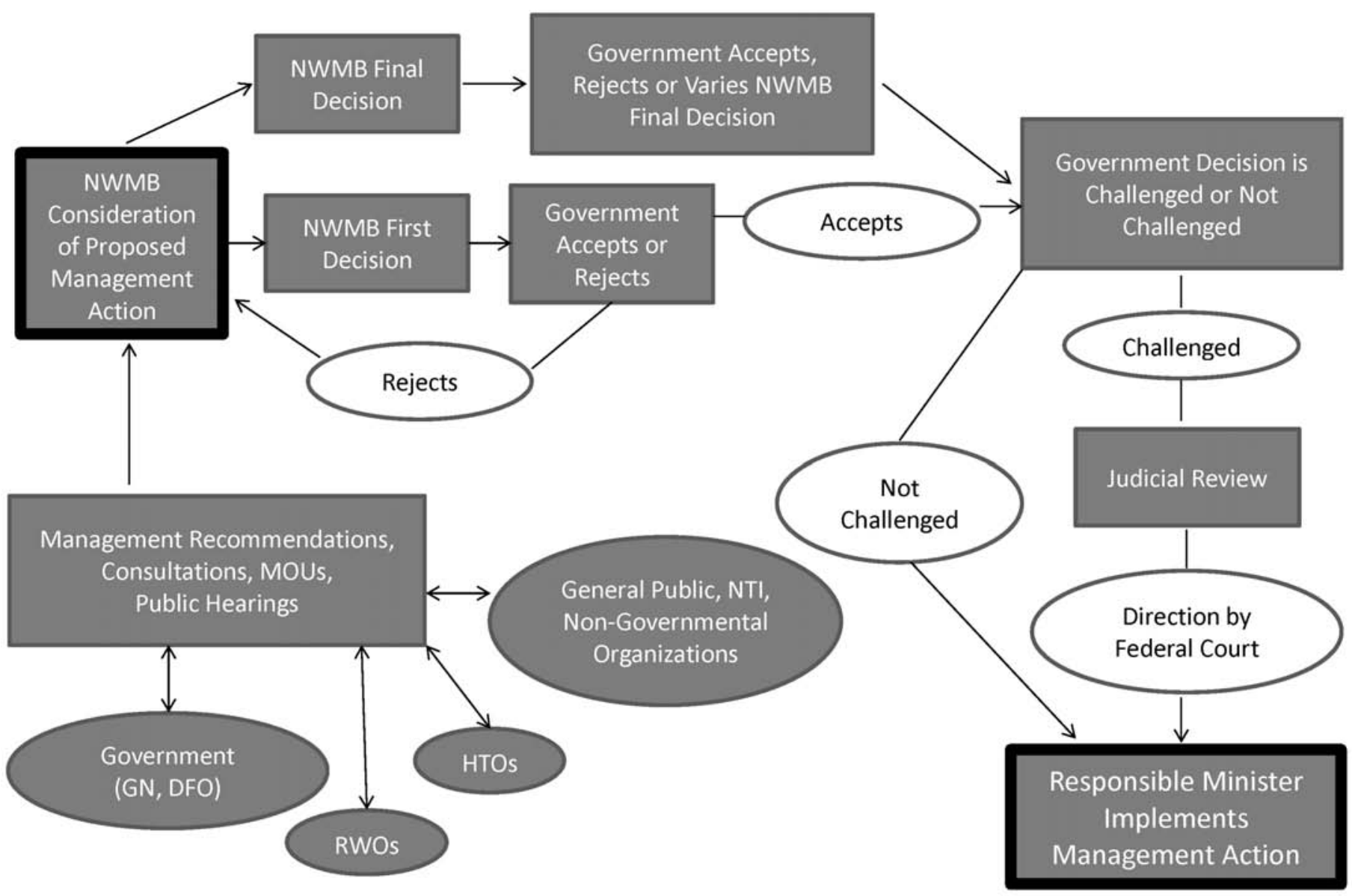

FIG. 3. Decision-making process for wildlife management under the Nunavut Land Claims Agreement. Source: Boudreau and Fanning (2016).

The HTO has independently developed its own whale harvesting management and safety guide, partly based on IQ values, such as requiring hunters to have participated in at least three previous hunts before striking a narwhal. Other communities have used this guide as a model for developing their own plans, and it has been useful in managing hunters visiting Naujaat from other communities.

\section{METHODS}

Primary data collection for this research consisted of 10 in-person, semi-structured interviews with relevant narwhal management stakeholders in Naujaat during a six-week field visit in June and July 2015. Questions to interviewees centered on three themes: (1) local hunting practices and knowledge sharing relating to narwhal harvesting; (2) changes in narwhal hunting and knowledge sharing over time; and (3) their perspective on the relationship of the hunting community with government managers. All individuals interviewed were current Inuit residents of Naujaat, comprising hunters (HTO members and staff), elders, and individuals with experience on IQ issues, most of whom had spent their entire lives in Naujaat or the surrounding area (Table 1). In most cases, interviewees fell into multiple categories. Interviews were conducted in either English or Inuktitut with the support of the project's community liaison, who is a lifelong resident of Naujaat and respected member of the community. The research was licensed by the Nunavut Research Institute and the Dalhousie University Research Ethics Board prior to commencing interviews. Immediately after each interview, audio recordings were used to produce detailed transcripts. Following the completion of the interviews, preliminary results were shared through local community radio. Listeners were invited to call in with comments, which were recorded and incorporated into the analysis; two callers contributed lengthy responses. This medium was selected because local radio is the primary means of mass communication in Naujaat and was anticipated to be the most effective way to reach a wide audience. Radio is particularly pertinent to the hunting community, as hunters will often use it to communicate their movements and successes to one another. The sample size of 10 interviews plus two radio commentaries was determined to be appropriate to the size of the community and the consistency of interviewee responses. Four interviews and the radio presentation were conducted in Inuktitut; the remaining six were in English. The same interpreter, who had been briefed on the research goals and objectives, 
TABLE 1. Age and status of the 10 interview respondents.

\begin{tabular}{lcccc}
\hline \hline Age (years) & Elder & Active hunter & Active hunter with HTO/RWO board experience & Other \\
\hline $20-40$ & - & 1 & 1 & - \\
$40-60$ & - & 1 & 2 & 1 \\
$60+$ & 4 & - & - & - \\
\hline \hline
\end{tabular}

1 “Other" refers to a respondent who had expertise in IQ but was neither an elder nor an active hunter.

was used for all Inuktitut interviews to ensure that the use of certain terms was consistent. The compiled results indicated sufficient consistency between the English and Inuktitut interview responses to control for bias on the part of the interpreter.

Interview transcripts were manually reviewed and initially coded for memories associated with narwhal harvesting; IQ concepts, principles, and knowledge; changes in narwhal harvesting; explanations of change; communication; community-based management; and ideas about the future. The coded groups were then organized into three broader categories according to theme and chronology (i.e., before the government-based management system; the period of change that has followed; and options for the future). The preliminary results presented over the radio were organized into these categories, and listener comments were coded and integrated into the results after the presentation.

\section{RESULTS}

Three categories emerged from the responses of interviewees: (1) memories and IQ relating to narwhal management (memories are included as an indicator of how IQ is acquired, used, and shared), (2) changes and external factors affecting IQ, and (3) ongoing concerns and options for the future.

\section{Memories and IQ Relating to Narwhal Management}

The comments relating to memories associated with narwhal and how IQ was and continues to be used ranged from specific hunting techniques, the organization of hunting activities broadly, knowledge transmission, and decision-making practices. Respondents explained that prior to government regulation, management decisions were informed by IQ, both when Inuit followed a mainly nomadic lifestyle and after the 1950s, when most Inuit resettled into permanent communities. Hunting efforts were managed according to the needs of the community, and the quantity of narwhal taken corresponded to the amount required for winter supplies, rather than to a predetermined quota or target. Several respondents explained that before government regulation, younger narwhal were the main targets of hunting because their meat and maktaaq have a more consistent quality than meat from older narwhals. When approaching a narwhal, hunters first harpooned the animal using a harpoon attached to a float, enabling hunters to shoot with greater accuracy. The entire carcass of the narwhal was used. Respondents generally equated these practices with the use of IQ to make decisions about harvesting.

Most respondents who could remember a time before government regulation reported that the pace of hunting and associated activities was significantly slower "when they were using the IQ system" (Respondent \#1). Often, hunters in the community would wait for pods of narwhal to swim into bays and observe them from shore before deciding whether and when to harvest. Hunting would take place when hunters were certain they would be successful. The first appearance of narwhal for the season did not mean that hunters would go out to pursue them right away. Hunting was co-operative rather than competitive: several hunters would work together to pursue, land, and butcher the animals, and the resources were shared.

One of the most common responses referred to a 'take only what you need' mentality that informed decision making prior to government regulation of narwhal hunting. Hunting took place only when food was needed for both people and sled dogs and ceased when enough supplies to last the winter had been gathered. This value forms part of the IQ knowledge about hunting, which is transmitted through families and shared between hunters. Several respondents who identified as hunters attributed their learning process to their elder relatives, who took them hunting as children. Elders also acted as mentors by passing on their knowledge, including practical issues (e.g., the correct areas to target on a narwhal), ecological information such as migration routes and changes in narwhal distributions, and values such as assisting other hunters in need and taking only what you need. Several respondents pointed out that written documentation is not part of the IQ system and that the knowledge is gained through hands-on experience, guided by more knowledgeable hunters. The act of hunting was identified as a critical component of maintaining and passing on IQ.

\section{Changes and Drivers of Change}

Every respondent with enough experience to recall the time before government regulation described significant changes to narwhal hunting since that time. The main changes described include the use of new and more efficient technologies, the monetization of hunting, the changing pace of hunting, and increased hunting pressures. The 
driving force behind these changes was identified as the introduction of the DFO quota system in the context of changing social conditions resulting from the ongoing effects of colonialism. Specific changes and their associated driving forces are summarized in Table 2.

Comments on changes observed in narwhal hunting over the past decades referred to environmental changes that have altered the usefulness of environmental knowledge associated with IQ. The changes described related to ice and weather patterns and shifts in narwhal migration routes and distribution. Technological shifts were considered a major contributor to overall changes in hunting practices. Snowmobiles have replaced dog teams as the primary means of transportation on sea ice, so narwhal meat is not used to feed dog teams anymore. The main objective of narwhal hunting now is to produce maktaaq for human consumption and acquire the tusk, which can be sold to provide the monetary income required to support a modern hunting lifestyle.

Several respondents pointed out that the availability of more powerful rifles, ammunition, and motorboats make narwhal hunting less labour-intensive, making narwhal hunting more popular now than in the past. One respondent also pointed out that as seal pelts have dramatically declined in value, narwhal hunting has become more financially worthwhile compared to other forms of hunting. This assessment was based on the costs of hunting relative to the returns available from the sale of the tusk and other products.

Most respondents also expressed concern about the changing pace of hunting. They have observed a shift from the slower pace of hunting and the practice of waiting for narwhal to come into shallow areas towards active pursuit of narwhal as soon as the tags for the season are available from the DFO. This shift is associated with safety concerns for both hunters and narwhal. Hunting today involves less planning and observation than in the past, which increases the chances that narwhal will be lost, compared to traditional methods of waiting until the hunter was certain of success. The driving force behind these changes was consistently identified as the introduction of the community quota system. Because each community has a specific number of tags for the season, hunters grow concerned about meeting their needs before the tags are used up, beginning to hunt as soon as tags are available rather than waiting for ideal conditions. One respondent pointed out that this rushed approach has altered the timing of traditional winter preparation activities. Prior to the introduction of the quota system, families were able to plan for the winter over a longer period of time, knowing that they would be able to hunt narwhal until the sea ice returned in the fall. Narwhal hunting was one of several activities undertaken simultaneously during the summer to prepare for winter. With the introduction of the quota system and a shift to a more rushed hunting season, narwhal has become the main priority from the time the tags are available until they are all gone.
Several respondents pointed out that more hunters are targeting narwhal than in the past, some of whom have very little experience with narwhal hunting, compromising the safety of both the species and other hunters. They attributed this change to both population growth in Naujaat and new hunters coming from other Nunavut communities to hunt in the Repulse Bay area. While having an allocation of the narwhal quota, these new hunters traditionally have not hunted narwhal and are less familiar with the IQ values and practices associated with narwhal harvesting. These comments were linked to concerns about the monetization of hunting activities, as the motivation for hunting shifted from food provision to income provision.

Many respondents were eager to convey that despite the changes they discussed, the central components of IQ will never change: these include practices about sharing maktaaq with other members in the community, co-operatively distributing the products of the hunt, and sharing hunting knowledge through families and between experienced and new hunters. However, regarding changes to the "take only what you need" approach that was identified as a fundamental principle in traditional decision making, several respondents expressed concerns that the quota system has pervasively changed the hunting mentality. They noted that hunters now focus primarily on individual concerns such as maximizing their catch before all the tags for the season have been used.

\section{Ongoing Issues and Options for the Future}

Respondents spoke of several ongoing issues in the field of narwhal management and provided suggestions as to how the management system could be improved to address them. The main concern was the effect of the quota system on narwhal hunting as described in the previous section. In almost every interview, respondents spoke at length about the negative impacts of the quota system. The "rushed" mentality and faster pace of hunting that have emerged in the past few decades were attributed to the quota system. It was noted that the desire to maximize each tag often leads to waste. One respondent recounted a story about catching a young narwhal and being pressured by other hunters to throw it away because they did not want to waste a tag on an animal with a small tusk and less maktaaq. Other key areas of concern included the need to establish more open communication with the DFO, especially regarding information and knowledge sharing; the possible benefits of establishing a community-based management system coordinated through the HTO; and the question of whether establishing a management system based on IQ could be feasible.

Respondents with experience in local-level management commented that they never saw the results of DFO narwhal studies, such as aerial population surveys, or had a sense that IQ was being used to inform DFO-level management decisions. One respondent suggested that community members would have a more positive impression of 


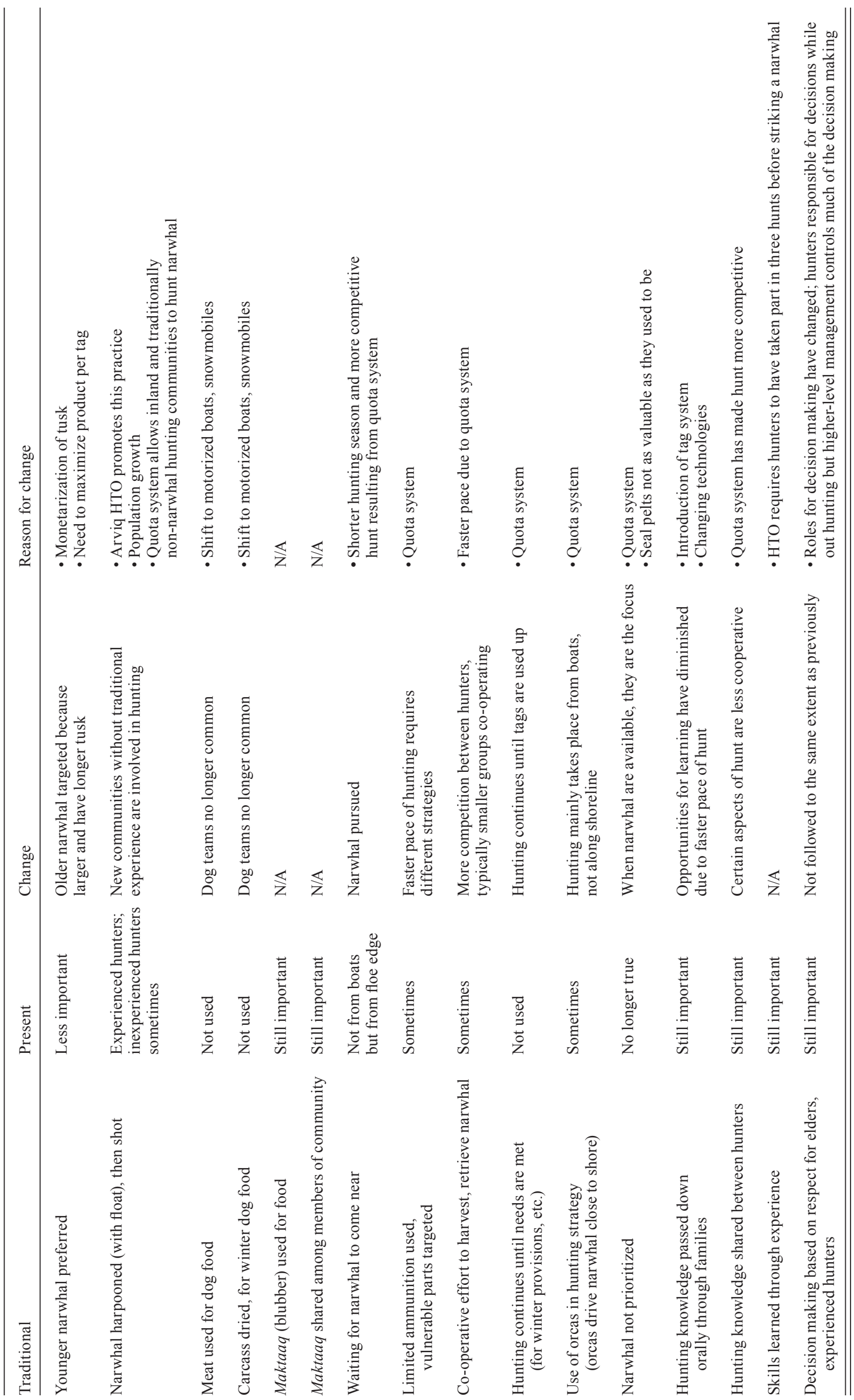


DFO decision making if they interacted more with the DFO, witnessed DFO representatives interacting with community members, and had the opportunity to share their knowledge with DFO managers. This perception is at odds with the fact that the DFO expanded the 2011 survey area on the basis of input from the Arviq HTO (Asselin et al., 2012). Respondents perceived a disconnect between the decisions that are passed down from the DFO and the actual state of narwhal resources. For example, in some years the annual quota is lowered while the hunters claim to see more narwhal than usual, yet information regarding how the quota decision was made is not communicated. When the DFO is present in the community, it is usually to conduct aerial surveys of the area to gather data about narwhal population size and distribution. Respondents commented that the DFO does not solicit advice from the community regarding the timing of these surveys to ensure that conditions are ideal. One respondent pointed out that local residents have an understanding of ice conditions and weather and could assist the DFO in determining when to carry out surveys, but that the DFO does not take advantage of this knowledge. This respondent also pointed out that when local people have concerns with narwhal management, they know how to contact the HTO to express their views, but they are not aware of how to bring such concerns forward to the DFO. It was suggested that the relationship with the DFO should involve both parties learning from and respecting each other to enable knowledge-sharing and educating DFO staff about IQ methods.

Another recurring issue identified by respondents was the challenges in bridging the gap between Western knowledge and IQ, especially regarding knowledge transmission. Respondents pointed out that IQ is shared orally and learned through experience, and suggested that if DFO managers wished to draw on IQ in decision making, they need to spend time with hunters and experience the hunt first-hand.

While acknowledging that the language used for resource management decision making (English) limited the extent to which IQ can be used, eight out of ten respondents suggested that management would be improved if local knowledge could be used in management decision making. The NWMB was identified as having a helpful role in advocating for Inuit interests, including those of specific communities, but one respondent with wildlife management experience explained that at times, the community still finds itself fighting to contribute input on management issues, including quota decisions. Many expressed interest in establishing community-based management directed by the local HTO or creating a power-sharing system in which the HTO has a greater share of control over particular management decisions, to facilitate a more collaborative relationship between the community, the DFO, and other higher-level management stakeholders. Respondents explained that providing communities with greater power over decision making would enable members of the community to utilize their specialized knowledge of local conditions. Some respondents pointed out that the HTO's leadership during Naujaat's experience with communitybased management led to positive outcomes, such as the development of locally based narwhal harvesting policies informed by IQ values that are still in use, indicating that the HTO's local-level management efforts are generally respected by community members and are a source of pride.

A common concern shared by several respondents, especially elders and older hunters, was that a management system based on IQ may not be effective in the modern context of narwhal harvesting because of increased population, changes in values, changes in hunting objectives (e.g., profit in addition to sustenance), new technologies, new mentalities towards hunting that have developed in response to the quota system, and changes in the distribution and behaviour of narwhal. Governmentbased management, despite its negative implications, was perceived to provide necessary services in light of these changes. Specifically, there were concerns raised that shifting control from the DFO to the local level to mobilize IQ would inhibit the enforcement of controls currently in place to prevent overharvesting. Respondents tended to view the DFO as having the stronger enforcement capacity needed to protect the narwhal population compared to local-level managers. Some respondents also recalled the negative aspects of their experience with community-based management, specifically how the number of narwhal hunted, as well as those struck and lost, was significantly higher than under the quota system. They worried that shifting decision-making power to the community would lead to the same result, because values have shifted away from the "take only what you need" mentality. Some respondents also stated that they did not anticipate that the DFO would be willing to create a power-sharing relationship and it was unrealistic to speculate about community-based management. Despite these criticisms, most respondents felt that the HTO should play a stronger role in management decision making (for example, by determining the quota themselves instead of having it imposed by the DFO) and in passing on hunting knowledge and creating hunter education programs.

\section{DISCUSSION}

The interview results suggest that government regulation of narwhal harvesting has ignored and undermined IQ in various ways. These can be categorized as (1) results of the imposed quota system, (2) the perception of the ongoing role for IQ, (3) communication challenges, (4) modernday drivers of change, and (5) the lack of decision-making authority at the community level.

The quota system has resulted in more competitive conditions and increased the pace of hunting, which has led to a change in values and limited opportunities for 
experiential knowledge sharing with new and younger hunters. The faster pace also increases the exposure of hunters to safety hazards and the risk that narwhal will be struck and lost rather than retrieved, thus affecting the sustainability of harvest levels. The objective of catching larger narwhal or those with the largest tusks to maximize the returns per tag may negatively affect narwhal populations by skewing the harvest towards the most fit males in the population. By disrupting the traditional pace and order of winter preparation activities, the quota system seems to disempower Inuit in the ability to use IQ in making decisions about harvesting at an individual level. The frustrations with these impacts of the quota system expressed by most respondents indicate that the current system for narwhal management not only excludes IQ, but also undermines IQ expression and transmission. This idea is reinforced by comparing interviewees' observed changes with specific IQ principles described in the Nunavut Wildlife Act (GN, 2003):

- Pilimmaksarniq/Ayoikyumikatakhimanik - that skills must be improved through experience and practice

- Piliriqatigiingniq/Havakatigiiklutik - that people must work together in harmony to achieve a common purpose

- Surattittailimaniq/Hugattittailimanik - that hunters should hunt only what is necessary for their needs and not waste the wildlife they hunt

When IQ is undermined, IQ holders and Inuit in the community are less able to adapt how IQ is expressed to suit the changing context and changing objectives for narwhal harvesting (Wenzel et al., 2008).

The influx of hunters from non-traditional narwhal hunting communities also alters how IQ is used at the community level. Prior to government regulation, narwhal harvests were limited to those who had spatial access to hunting areas, but the quota-based approach fails to draw on this aspect of IQ. While it may not be feasible to restrict these "new" communities that have more recently begun to access narwhal harvesting areas, there may be management tools other than quotas that could effectively control hunting effort while also drawing on IQ principles. Under the NLCA, the Naujaat HTO's policies apply only to its members; therefore, the HTO does not control the release of tags allocated to other communities, and visiting hunters are not directly subject to the local HTO by-laws.

It is evident that the quota system prevents overharvesting for the short term by limiting harvest levels and that, collectively, the main concern of most stakeholders in narwhal management is protecting the narwhal population. A more collaborative management system would appear to be beneficial to both government managers and hunters (Armitage et al., 2011).

The eagerness most interview respondents expressed in conveying that IQ "will never change" is indicative of the importance of the values and practices associated with IQ as an integral component of Inuit cultural identities.
Practices that continue to influence hunting activities, such as decision-making protocols within hunting groups, speak to the continued relevance, importance, and utility of the IQ system (Reo and Whyte, 2012).

References to poor communication with the DFO indicate a lack of empowerment of Inuit within the management system (ITK, 2017). Inuit community stakeholders are not well informed about the rationale for DFO's management decisions, although these decisions directly affect Inuit livelihoods and inhibit the ability of Inuit within communities to engage with the management process (Nadasdy, 2003). Lack of engagement prevents the mobilization and communication of IQ from the scale of individual hunters or the local hunting community to the overall decision-making structure. Ineffective communication also contributes to a lack of trust between Inuit hunters and DFO-level management, which impedes knowledge-sharing opportunities between the two groups and limits the effectiveness of management (Furgal et al., 2002; Wenzel et al., 2008).

Inuktitut is part of the IQ system as the language in which the knowledge system is expressed, but the existing management system in Canada is derived from a Western paradigm of resource management that has emerged primarily through the use of the English language. In order to communicate knowledge obtained through IQ, Inuit are typically required to translate concepts into English, a language that has evolved to express an entirely different worldview. This translation skews the way that Inuit knowledge is understood and thus how it is used in management. In order to adequately convey IQ knowledge, it must be expressed in its original form. Giles et al. (2016), in their study on the importance of language, came to a similar conclusion: that the original language is necessary to fully understand the Mi'kmaq knowledge system as it relates to eel harvesting. It is unlikely that the existing management system will adopt Inuktitut as the language for decision making, but empowering Inuit to hold greater decision-making power at a lower level in the management system would provide an opportunity to use Inuktitut in the decision-making process. In the current system, Inuit attempting to express knowledge gained through IQ are at a disadvantage because they must translate this knowledge into languages that reflect an entirely different worldview (White, 2006; Battiste, 2009).

Changes in the technologies used in narwhal harvesting, population growth, environmental changes, and the increasing need for a monetary income have altered the context for the use of IQ, independently of the influence of the government narwhal regulation system. Empowering Inuit in narwhal management could create opportunities to use IQ in responding to such changes in ways that are culturally acceptable and allow Inuit to determine management objectives that reflect their needs. This empowerment could have the added benefit of using management to strengthen the IQ system within a changing context (Berkes, 2009a). 
A collaborative system that allocates more power to the community level could build trust between co-management partners and create the conditions for knowledge sharing (Berkes, 2009b). New approaches to engaging community members in research activities and community consultations are one opportunity to begin to work towards greater collaboration. In spite of the DFO's existing communication efforts (e.g., consulting the HTO in survey planning), community members evidently perceive poor communication, a lack of trust, and a lack of engagement as key problems. The continuing support of higher-level management for community-based management measures would also provide important enforcement abilities and help to strengthen the system against potential pressures from international anti-whaling interests.

\section{CONCLUSION}

Effective resource management must account for the needs and objectives of the primary resource users, which includes using their knowledge as a basis for decision making. In the case of narwhal management in Nunavut, mobilizing IQ in management decision making requires that Inuit be empowered at the local level to make decisions that reflect their experiential knowledge of the resource. The current narwhal management system fails to empower Inuit and to adequately integrate IQ. Instead, the system has some components that serve to undermine IQ values and practices and it is plagued by ineffective and insufficient communication and collaboration between community-based stakeholders and higher-level managers. The final decision-making power rests with the federal government, limiting the ability of Inuit to effect change and take responsibility for the resources that sustain their livelihoods. An improved management system would concentrate more power with community-level managers so that decision making could draw on IQ. It would also better reflect the needs and objectives of Inuit, in keeping with commitments from both the territorial and federal levels of government to draw on traditional knowledge in decision making and management.

The findings of this case study in Naujaat have significance for harvesting of other species and for other communities in Nunavut and can inform the development of management systems that empower, rather than marginalize, Indigenous knowledge holders. Future areas of inquiry stemming from this research could address the relationship between the narwhal case study and broader wildlife management issues in Nunavut and investigate the experiences of hunters in other Nunavut communities to understand differences and trends across the territory. As Nunavut continues to experience rapid population growth, hunting pressures on many wildlife species are increasing, reinforcing the need to establish effective and equitable systems for management of fisheries and wildlife.

\section{ACKNOWLEDGEMENTS}

The authors extend sincere gratitude to the Arviq Hunters and Trappers Organization, the people of Naujaat, and all the participants for their interest in and contributions to this project. We also thank the Nunavut Wildlife Management Board, Nunavut Research Institute, Arctic College, and Parks Canada for their assistance during the field component of the research. Funding for this study was provided by the Social Sciences and Humanities Research Council of Canada (SSHRC).

\section{REFERENCES}

Armitage, D.R. 2005. Community-based narwhal management in Nunavut, Canada: Change, uncertainty, and adaptation. Society \& Natural Resources 18(8):715-731. https://doi.org/10.1080/08941920591005124

Armitage, D.R., Berkes, F., Dale, A., Kocho-Schellenberg, E., and Patton, E. 2011. Co-management and the co-production of knowledge: Learning to adapt in Canada's Arctic. Global Environmental Change 21(3):995-1004.

https://doi.org/10.1016/j.gloenvcha.2011.04.006

Asselin, N.C., Ferguson, S.H., Richard, P.R., and Barber, D.G. 2012. Results of narwhal (Monodon monoceros) aerial surveys in northern Hudson Bay, August 2011. Canadian Science Advisory Secretariat Research Document 2012/037. Winnipeg, Manitoba: Fisheries and Oceans Canada.

http://waves-vagues.dfo-mpo.gc.ca/Library/347183.pdf

Battiste, M. 2009. Reclaiming Indigenous voice and vision. Vancouver: UBC Press.

Berkes, F. 2009a. Indigenous ways of knowing and the study of environmental change. Journal of the Royal Society of New Zealand 39(4):151-156. https://doi.org/10.1080/03014220909510568

- 2009b. Evolution of co-management: Role of knowledge generation, bridging organizations and social learning. Journal of Environmental Management 90(5):1692-1702. https://doi.org/10.1016/j.jenvman.2008.12.001

Boudreau, S.A., and Fanning, L.M. 2016. Nunavut fisheries co-management and the role of the Nunavut Land Claims Agreement in fisheries management and decision making. Ocean Yearbook 30(1):207-241.

CITES (Convention on the International Trade in Endangered Species of Wild Fauna and Flora). 1973. Washington, D.C.: International Union for Conservation of Nature.

Corntassel, J. 2012. Re-envisioning resurgence: Indigenous pathways to decolonization and sustainable self-determination. Decolonization: Indigeneity, Education \& Society 1(1):86-101.

COSEWIC (Committee on the Status of Endangered Wildlife in Canada). 2004. COSEWIC assessment and update status report on the narwhal Monodon monoceros in Canada. Ottawa: COSEWIC.

Dale, A., and Armitage, D. 2011. Marine mammal co-management in Canada's Arctic: Knowledge co-production for learning and adaptive capacity. Marine Policy 35(4):440-449.

https://doi.org/10.1016/j.marpol.2010.10.019 
Denny, S.K., and Fanning, L.M. 2016. A Mi'kmaw perspective on advancing salmon governance in Nova Scotia, Canada: Setting the stage for collaborative co-existence. The International Indigenous Policy Journal 7(3): Art. 4. https://doi.org/10.18584/iipj.2016.7.3.4

DFO (Fisheries and Oceans Canada). 2013. Integrated Fisheries Management Plan (IFMP) for narwhal in the Nunavut settlement area. Winnipeg, Manitoba: DFO.

- 2015. Abundance estimates of narwhal stocks in the Canadian High Arctic in 2013. Canadian Science Advisory Secretariat Science Advisory Report 2015/046. Winnipeg, Manitoba: DFO. http://waves-vagues.dfo-mpo.gc.ca/Library/365100.pdf

Ferguson, S.H., Higdon, J.W., and Westdal, K.H. 2012. Prey items and predation behavior of killer whales (Orcinus orca) in Nunavut, Canada based on Inuit hunter interviews. Aquatic Biosystems 8(3). 16 p. https://doi.org/10.1186/2046-9063-8-3

Freeman, M.R., Bogoslovskaya, L., Caulfield, R.A., Egede, I., Krupnik, I.I., and Stevenson, M.G. 1998. Inuit, whaling, and sustainability. London: AltaMira Press.

Furgal, C.M., Innes, S., and Kovacs, K.M. 2002. Inuit spring hunting techniques and local knowledge of the ringed seal in Arctic Bay (Ikpiarjuk), Nunavut. Polar Research 21(1):1-16. https://doi.org/10.3402/polar.v21i1.6470

Giles, A., Fanning, L., Denny, S., and Paul, T. 2016. Improving the American eel fishery through the incorporation of Indigenous knowledge into policy level decision making in Canada. Human Ecology 44(2):167-183. https://doi.org/10.1007/s10745-016-9814-0

GC (Government of Canada). 1993. Nunavut Land Claims Agreement Act (S.C. 1993, c. 29).

GN (Government of Nunavut). 2003. Nunavut Wildlife Act, S.Nu. 2003, c. 26.

- 2008. Nunavut coastal resource inventory: Iglulik pilot project. Iqaluit: Department of Environment, Fisheries and Sealing Division.

Gonzalez, N. 2001. Inuit traditional ecological knowledge of the Hudson Bay narwhal (Tuugaalik) population. Prepared for Fisheries and Oceans Canada, Iqaluit, Nunavut. http://www.dfo-mpo.gc.ca/Library/317649.pdf

Hamlet of Naujaat. 2015. Repulse Bay on the Arctic Circle: Town and information.

https://www.repulsebay.ca/information.html

Heide-Jørgensen, M.P., Hansen, R.G., Westdal, K., Reeves, R.R., and Mosbech, A. 2013. Narwhals and seismic exploration: Is seismic noise increasing the risk of ice entrapments? Biological Conservation 158:50-54. https://doi.org/10.1016/j.biocon.2012.08.005

Higdon, J.W., and Ferguson, S.H. 2009. Loss of Arctic sea ice causing punctuated change in sightings of killer whales (Orcinus orca) over the past century. Ecological Applications 19(5):1365-1375. https://doi.org/10.1890/07-1941.1
Hoover, C., Bailey, M., Higdon, J., Ferguson, S.H., and Sumaila, R. 2013. Estimating the economic value of narwhal and beluga hunts in Hudson Bay, Nunavut. Arctic 66(1):1-16. https://doi.org/10.14430/arctic4261

Huntington, H.P. 2005. "We dance around in a ring and suppose": Academic engagement with traditional knowledge. Arctic Anthropology 42(1):29-32. https://doi.org/10.1353/arc.2011.0101

Hurtubise, J. 2016. Evolution of subsistence and commercial Inuit fisheries in the Territory of Nunavut: Research and summation of landings, quotas, gear type, significance, use and status of hunted marine species. Marine Affairs Program Technical Report 14.

https://cdn.dal.ca/content/dam/dalhousie/pdf/faculty/ science/marine-affairs-program/Technical_series/ MAPTechnicalReport14.pdf

ITK (Inuit Tapiriit Kanatami). 2017. ITK position paper: Implementing the UN declaration on the rights of Indigenous peoples. Ottawa: ITK.

https://www.itk.ca/implementing-the-un-declaration-on-therights-of-indigenous-peoples/

Laidre, K.L., Stirling, I., Lowry, L.F., Wiig, Ø., Heide-Jørgensen, M.P., and Ferguson, S.H. 2008. Quantifying the sensitivity of Arctic marine mammals to climate-induced habitat change. Ecological Applications 18(sp2):S97-S125.

https://doi.org/10.1890/06-0546.1

Laidre, K., Stern, H., Kovacs, K.M., Lowry, L., Moore, S.E., Regehr, E.V., Ferguson, S.H., et al. 2015. Arctic marine mammal population status, sea ice habitat loss, and conservation recommendations for the 21st century. Conservation Biology 29(3):724-737.

https://doi.org/10.1111/cobi.12474

McLeish, T. 2013. Narwhals: Arctic whales in a melting world. Seattle: University of Washington Press.

Nadasdy, P. 2003. Hunters and bureaucrats: Power, knowledge, and Aboriginal-state relations in the Southwest Yukon. Vancouver: UBC Press.

NWMB (Nunavut Wildlife Management Board). 2012. Decision database: Integrated Fisheries Management Plan for narwhal in the Nunavut Settlement Area (Monodon monoceros). Working draft (Revision \#6) Narwhal IFMP - April 24th, 2012. (Effective January 2013). Public Hearings Registry, 022TAB 19.

http://www.nwmb.com/en/public-hearings-a-meetings/ public-hearings-1/2012-1/proposed-integrated-fisheriesmanagement-plan-for-narwhal-in-the-nunavut-settlementarea-including-the-establishment-of-total-allowable-harvestsbasic-needs-levels-and-non-quota-limitations-july-24th-26th/ proposal-for-nwmb-decision-and-supporting-evidence5? limit $=25 \&$ limitstart $=25$

Phelps Bondaroff, T.N., and Burke, D.C. 2014. Bridging troubled waters: History as political opportunity structure. Journal of Civil Society 10(2):165-183.

https://doi.org/10.1080/17448689.2014.919179 
Reo, N.J., and Whyte, K.P. 2012. Hunting and morality as elements of traditional ecological knowledge. Human Ecology 40(1):15-27. https://doi.org/10.1007/s10745-011-9448-1

Richard, P. 2001. Marine mammals of Nunavut. Iqaluit: Qikiqtani School Operations, Nunavut Department of Education.

Rodon, T. 1998. Co-management and self-determination in Nunavut. Polar Geography 22(2):119-135. https://doi.org/10.1080/10889379809377641

Russell, P.H. 1997. Aboriginal nationalism and Quebec nationalism: Reconciliation through fourth world decolonization. Constitutional Forum 8:110-118.

Sejersen, F. 2001. Hunting and management of beluga whales (Delphinapterus leucas) in Greenland: Changing strategies to cope with new national and local interests. Arctic 54(4):431-443. https://doi.org/10.14430/arctic800

Shadbolt, T., Cooper, E.W.T., and Ewins, P.J. 2015. Breaking the Ice: International trade in narwhals, in the context of a changing Arctic. Toronto: TRAFFIC North America and World Wildlife Fund-Canada.

Simpson, L.R. 2004. Anticolonial strategies for the recovery and maintenance of Indigenous knowledge. American Indian Quarterly 28(3-4):373-384. https://doi.org/10.1353/aiq.2004.0107

Statistics Canada. 2016. Nunavut census profile, 2016 census. http://www12.statcan.ca/census-recensement/2016/dp-pd/ prof/search-recherche/lst/results-resultats.cfm?Lang=E\&TA $\mathrm{BID}=1 \& \mathrm{G}=1 \& \mathrm{Geo} 1=\& \mathrm{Code} 1=\& \mathrm{Geo} 2=\& \mathrm{Code} 2=\& \mathrm{GEOCO}$ $\mathrm{DE}=62$
Stevenson, M.G. 2004. Decolonizing co-management in northern Canada. Cultural Survival Quarterly Spring 2004:68-71.

Tellis, W.M. 1997. Application of a case study methodology. The Qualitative Report 3(3):1-17.

Tester, F.J., and Irniq, P. 2008. Inuit Qaujimajatuqangit: Social history, politics, and the practice of resistance. Arctic 61 (Suppl. 1):48-61. https://doi.org/10.14430/arctic101

UN (United Nations). 2008. The United Nations declaration on the rights of Indigenous peoples.

http://www.un.org/esa/socdev/unpfii/documents/

DRIPS_en.pdf

Wenzel, G.W. 1995. Warming the Arctic: Environmentalism and the Canadian Inuit. In: Peterson, D.L., and Johnson, D.R., eds. Human ecology and climate change: People and resources in the Far North. Washington D.C.: Taylor \& Francis. 169-184.

. 2004. From TEK to IQ: Inuit Qaujimajatuqangit and Inuit cultural ecology. Arctic Anthropology 41(2):238-250. https://doi.org/10.1353/arc.2011.0067

Wenzel, G., Weihs, F., and Rigby, G. 2008. The use of traditional ecological knowledge and IQ in the management of wildlife in Nunavut: A critical review. Prepared for the Nunavut Wildlife Management Board, Iqaluit, Nunavut.

White, G. 2006. Cultures in collision: Traditional knowledge and Euro-Canadian governance processes in northern land-claim boards. Arctic 59(4):401-414. https://doi.org/10.14430/arctic289

Yin, R.K. 2013. Case study research: Design and methods, 5th ed. Thousand Oaks, California: Sage Publications 